\title{
SOBRE LA LITERATURA DE LA EMANCIPACIÓN EN EL PERÚ
}

\author{
Por \\ ANTONIO CORNEJO POLAR \\ Universidad Nacional \\ Mayor de San Marcos
}

En sus encontrados exámenes de la literatura peruana, Riva Agüero y Mariátegui coinciden en un solo punto: en que la independencia, en 1821, no produjo transformaciones en el proceso de una literatura que siguió sin mayores sobresaltos la tradición colonial. ${ }^{1}$ Este acercamiento, que está sujeto y limitado a la verificación de ciertos hechos literarios evidentes a simple lectura, desaparece de inmediato para dar paso a interpretaciones y valoraciones radicalmente opuestas. No en vano Riva Agüero propiciaba una literatura de raíz, forma y espíritu hispánicos, mientras Mariátegui postulaba la necesidad de negar el colonialismo, superar el cosmopolitismo y fundar una literatura nacional fuertemente adherida a las reivindicaciones indígenas. ${ }^{2}$ De todas maneras, la inusual convergencia de pensamientos tan disímiles, permite partir de un cierto grado de evidencia y hace innecesaria la descripción pormenorizada de sus referencias textuales. Tal no implica, sin embargo, que detrás de un juicio básicamente correcto: la independencia no generó cambios decisivos en el sistema literario precedente, no se esconda una problemática densa y compleja, especialmente atractiva porque permite diseñar articulaciones varias - y distintas - entre la sociedad y la literatura de una misma coyuntura histórica.

Las páginas que siguen proponen algunos criterios para una nueva interpretación de esta literatura. Suponen, aunque tal vez demasiado elípticamente, dos convicciones: una teórica, relativa a la pluralidad convergente de los vínculos que asocian la literatura a la sociedad, y otra, más bien histórica, que se refiere al espesor y a la estratificación de las literaturas latinoamericanas, casi siempre malentendidas por una crítica que uniforma lo que en realidad es múltiple y heterogéneo.

1. José de la Riva Agüero, Carácter de la literatura del Perú independiente,(Lima: Rosay, 1905). José Carlos Mariátegui: Siete ensayos de interpretación de la realidad peruana, (Lima, Amauta, 1928).

2. Cf. mi artículo, "El problema nacional en la literatura peruana" (en: Que Hacer, 4, Lima: abril 1980). 


\section{LA EMANCIPACIÓN: TEMAS Y REFERENTES}

Pese a la continuidad del proceso literario entre la colonia y la república, las historias de la literatura peruana suelen consignar un capítulo dedicado a la "literatura de la emancipación". Aunque en ningún caso se caracteriza suficientemente lo que se entiende bajo esa denominación, es claro que se trata de un periodo de límites harto difusos y que su definición se basa en la relación existente entre un conjunto de obras literarias y los hechos e ideas que constituyen un segmento de la historia general del Perú: aquéllos que giran alrededor de 1821, antecediendo $y$ haciendo posible la declaración de la independencia o inmediatamente consecuentes a la fundación de la república. En alguna ocasión esta relación apenas se menciona $y$ en ese caso "literatura de la emancipación" es la que cronológicamente coincide con ese momento histórico, aunque con él no guarde ligazón alguna.

Si se prescinde de este último criterio, por lo demás insostenible, queda en pie, como carácter propio de la "literatura de la emancipación", ese vínculo que asocia a un conjunto literario más o menos nutrido con los acontecimientos e ideología de la independencia. Aunque en la práctica suelen darse unidas, se trata en principio de dos opciones diferentes: una tiene que ver con los textos que describen, comentan o valoran los sucesos de la emancipación, como pueden ser las conspiraciones, las batallas o los actos de juramentación y festejo de la independencia, y otra se refiere a las obras que de una $u$ otra forma expresan las distintas alternativas ideológicas de la época y que convergen hacia un breve elenco de valores como los de libertad, independencia, soberanía, etc. Sería legítimo considerar que en la primera alternativa la emancipación funciona sobre todo como referente y en la segunda, más bien, como tema. Este deslinde funciona a lo largo de las distintas etapas por las que transcurre la "literatura de la emancipación".

El corpus que surge de esta doble delimitación es más o menos homogéneo y relativamente cuantioso, sobre todo si se incorporan a él las obras que a partir de 1812 despliegan el liberalismo triunfante en las Cortes de Cádiz y las que se hacen eco, a veces tardío, de las victorias de Junín y Ayacucho (1924). En general, sin embargo, se trata de textos circunstanciales, de importancia menor, cuyo lustre se ha ido desgastando con el tiempo. Ciertamente subsisten obras valiosas, como las poesías patrióticas de Mariano Melgar (1790-1815), que acompañan el proceso “precursor” hasta la rebelión de Pumacahua (1814), las del ecuatoriano José Joaquín Olmedo (1780-1847), muy ligado a la historia y la literatura del Perú, especialmente su renombrada oda "A la victoria de Junín” (1826), o también, en otros géneros, algunos textos de los ideólogos independentistas. 


\section{EL PROBLEMA DE LA FORMA}

El concepto de "literatura de la emancipación" diseñado en los párrafos anteriores es simple y no parece suscitar mayores problemas. Sin embargo, apenas se trata de relacionar las instancias temático-referenciales con las formales, ausentes por completo en esa conceptualización, surgen conflictos importantes. Dicho en trazos gruesos, el asunto se resume así: las obras que asumen la emancipación como tema y/o referente repiten sin variantes la norma del neoclasicismo español, y en esa repetición no se perciben rasgos de una conciencia que señale la contradicción que subyace en el acatamiento de tal modelo. No está demás recordar, como ilustración complementaria, que un periódico tan liberal, independentista y antiespañol como La abeja republicana se anuncia bajo el epígrafe de unos versos patrióticos de Quintana. ${ }^{3}$

Desde este punto de vista, la "literatura de la emancipación" se define por una contradicción evidente: el nuevo repertorio de temas y referentes, alusivo a la independencia y teñido de agresividad frente a España, se procesa literariamente con sumiso acatamiento a las normas estéticas peninsulares - como volverá a suceder, con no muchas variantes, a propósito del combate del Callao (1866). Es muy esclarecedor que "A la victoria de Junín", que es "la más cabal expresión... de la poesía patriótica que representa el ciclo de la emancipación", ${ }^{4}$ deje ver sin dificultad su ancestro hispánico y su obediencia al canon neoclásico. ${ }^{5} \mathrm{Y}$ esto que se trata de Olmedo, calificado por Sánchez como el "único" poeta de la revolución de la independencia, que en algún momento afirma descreer de las "luces, costumbres, religión y leyes" que impusieron los españoles en América. ${ }^{6}$ Lo cierto es que su canto a la libertad y a la independencia supone una actitud cultural que delata, precisamente, lo contrario. Por cierto, esta contradicción no tanto desmerece la obra de Olmedo, la más valiosa de ese momento, cuanto revela la confusa ambigüedad de su contorno histórico.

Se trata de una contradicción de verdad significativa. Detrás de estos textos que afirman independencia y autonomía, que imprecan contra el oscurantismo español, y que sin embargo son en sí mismos producto de la dependencia con respecto a España, existen conflictos irresueltos que van mucho más allá del campo literario. No se explica la contradicción ni

3. Existe una excelente edición facsimilar, con prólogo y notas de Alberto Tauro (Lima: Copé, 1971)

4. Alberto Tauro, Elementos de literatura peruana (Lima: Palabra, 1946), p. 60.

5. Las especificó Marcelino Menéndez Pelayo (Historia de la poesía hispanoamericana, Madrid, Suárez, 1911-1913, $2 \mathrm{tms}$ ) y han sido confirmadas por toda la critica posterior.

6. Luis Alberto Sánchez: Los poetas de la Colonia y de la Revolución (Lima: Universo, 1974), p. 293. La 1ra. versión data de 1919. 
subrayando la inmadurez de la literatura peruana del momento, ni poniendo de relieve la influencia que tuvo la literatura española constitucionalista, liberal y antinapoleónica sobre la peruana, ${ }^{7}$ aunque ambos juicios sean correctos. Después de todo, para cotejar con un solo hecho, la literatura argentina también era incipiente y recibió la misma influencia, pero ensayó otros rumbos, sea mediante la sustitución del modelo hispánico por el francés y con el cambio de la poética neoclásica por la romántica, sea mediante el empleo de raíces populares para la invención de la poesía gauchesca. La explicación tiene que ser otra.

\section{LOS LIMITES DE LA INDEPENDENCIA}

A finales de la década del 60 y a comienzos de la siguiente, con motivo de la conmemoración del sesquicentenario de la independencia del Perú, en las ciencias sociales fue visible una vasta movilización destinada a reinterpretar el sentido de aquel hecho histórico. En discusión abierta con el pensamiento oficial, como siempre dispuesto a la pura celebración, se difundió entonces una imagen crítica del proceso emancipador. Dos fueron los aspectos fundamentales puestos de relieve: de una parte, la comprobación de la escasa y fluctuante participación popular en el proceso que condujo a la independencia; de otra, la delimitación de las repercusiones de este hecho al campo político y su irrelevancia en términos sociales y económicos - juicio que había adelantado Mariátegui muchos años antes. ${ }^{8}$ La bibliografía acumulada al respecto, cuyas conclusiones se asumen en este trabajo, permite prescindir de una exposición detallada. 9

\section{LITERATURA Y SOCIEDAD (I)}

Lo dicho hasta aquí ofrece la posibilidad de trazar una asociación genérica entre los límites de la "literatura de la emancipación", en cuanto su sumisión al código español recorta el carácter independentista de sus

7 Cf. Luis Monguió; "La poesía y la Independencia, Perú: 1808- 1825" (en: Literatura de la Emancipación Hispanoamericana y otros ensayos. (Memoria del XV Congreso del Instituto de Literatura Iberoamericana), Lima: Universidad de San Marcos, 1972.

8. En Siete ensayos... hay numerosas referencias a este hecho.

9. Estudios de Bonilla, Chaunu, Halperin, Hobsbawn, Spalding y Vilar están recogidos en el volumen colectivo La independencia en el Perú, (Lima: Instituto de Estudios Peruanos, 1972). Cf. también los estudios de José Ignacio López Soria, especialmente La descomposición de la dominación hispánica en el Peru (Lima: Arica, 1973). El gobierno, a través de la Comisión Nacional del Sesquicentenario de la Independencia, editó una extensa serie de documentos precedidos por prólogos importantes, aunque en la mayoría de los casos se trata de estudios más bien tradicionales. 
temas y referentes, y los límites del proceso histórico que le corresponde, en tanto ese proceso no modifica la estructura de base de la sociedad peruana. Se trata de una asociación puramente indiciaria, sin duda, pero ella da pie a una exploración más concreta y profunda.

El núcleo del problema parece residir en la contradicción ya mencionada varias veces: la dependencia formal, con respecto al código español, de una literatura que plasma un sentido independentista en sus estratos referenciales $\mathrm{y} / \mathrm{o}$ temáticos. Ciertamente, desde una perspectiva contenidista, se trataría de una contradicción menor, hasta irrelevante, porque el carácter emancipador estaría impreso en los planos decisivos de ese conjunto literario; sin embargo, aun si eventualmente se aceptara esa jerarquización, el conflicto se mantendría vigente: no deja de ser contradictorio $-\mathrm{y}$ mucho- que un discurso que dice independencia se configure como un acto de dependencia, sobre todo si esa dependencia se inscribe en el espacio que, por su propio carácter estético, podria admitir la realización de un programa de experimentación de nuevos rumbos acordes con la intencionalidad manifiesta de los otros estratos.

Como queda insinuado, la contradicción visible en el plano literario parece reproducir la contradicción, menos clara pero más decisiva, del proceso social correlativo: aquí también la independencia se obtiene en un cierto nivel, el político, pero no en otros como el social y el económico. En esta relación de reproducción cabría objetar la inversión de las categorías puestas en juego: en el plano real cambia la superestructura política y se mantiene la base económico-social, mientras que en el plano literario cambia el "fondo" o "contenido" (que parecería corresponder a la estructura de base) y se mantiene la forma (asociable a la superestructura). En realidad, sin embargo, esta doble asociación sólo puede derivar del contenidismo, pues, si se trata de comparar las categorías mencionadas, es la forma literaria la que equivale, en cuanto cimiento material de la producción estética, a la estructura de base en el campo social. En última instancia, en efecto, es el lenguaje y su modo de organización la categoría que determina objetivamente las construcciones semánticas que el texto propone a los lectores. Está demás advertir que esto no supone imaginar al lenguaje como una fuerza fundadora actuante en el vacío.

Naturalmente la reproducción literaria de los hechos sociales no es ni mecánica ni automática. Por esto, desde una perspectiva complementaria, los límites de la "literatura de la emancipación" deben remitirse también a la conciencia de los grupos sociales que formularon o se adhirieron y ejecutaron o colaboraron en ese - y no otro- proyecto independentista; vale decir, a la conciencia de ciertas fracciones de los grupos criollos más poderosos, interesados en que la emancipación les abriera la cúpula del ejercicio político y algunos espacios burocráticos y económicos monopoli- 
zados por el poder colonial y la aristocracia española, pero en modo alguno dispuestos a variar a fondo un orden social que los favorecía ampliamente. De aquí que el programa de la emancipación no incluyera ninguna reivindicación sustancial del pueblo y menos de las masas indígenas. En este orden de cosas, la "literatura de la emancipación" expresa la restricción con que esos grupos concibieron la independencia: es, por esto, una de sus manifestaciones ideológicas más evidentes.

\section{LOS YARAVIES: OTRA ALTERNATIVA}

Tal como efectivamente se produjo, la "literatura de la emancipación" tiene que remitirse tanto a la realidad del proceso histórico que le corresponde, cuya estructura reproduce, cuanto a la ideología -que expresa con explicitez- de los grupos que lo gobernaron. Este tipo de literatura no cubre, sin embargo, todo el campo de la actividad literaria que tiene que ver con la emancipación. Los yaravíes de Melgar son la otra alternativa; ${ }^{10}$ representan, en términos generales, el vértice del subsistema literario que la crítica suele eludir, maljuzgar o - lo que es peorhomologar con la tradición erudita y oficial.

Como se sabe, la poesía patriótica de Mariano Melgar está incorporada al orden neoclásico y reitera los caracteres de la "literatura de la emancipación", tal como han sido descritos y explicados anteriormente, aunque en algún caso sea posible detectar algunas desviaciones de esa norma. ${ }^{11}$ Empero, al lado de esta poesía, y esto es lo que ahora interesa, Melgar produjo una apreciable cantidad de breves canciones amorosas que se conocen bajo la denominación de yaravíes. La crítica sobre este género todavía no ha definido suficientemente su historia y caracteres, ${ }^{12}$ pero, en todo caso, es posible establecer ya algunos criterios básicos.

Es importante subrayar, por lo pronto, que el yaraví surge de una matriz indígena prehispánica, aunque no haya consenso acerca del tipo concreto

10. Mariano Melgar: Poesías completas (Lima: Academia Peruana de la Lengua, 1971). Incluye 71 yaravíes, en algunos casos de atribución dudosa. Cf.: Aurelio Miró Quesada: Historia y leyenda de Mariano Melgar (Madrid: Centro Iberoamericano de Cooperación, 1978).

11. "En una noche oscura y pavorosa" (Poesias Completas, Op. cit. pp. 60-62) es un texto inusual por la presencia de notas que explicitan el carácter subversivo de algunas alusiones contenidas en los versos del poema.

12 Cf. la muy completa "Bibliografía" de Estuardo Núñez incluida como apéndice en Poesías Completas (Op. cit. pp. 519-534). Hay que añadir algunos estudios posteriores: Antonio Cornejo Polar: "La poesía de Melgar y la emancipación" (en El Peruano (edición extraordinaria), Lima, 28 julio 1971) Juan Guillermo Carpio Muñoz: El yaraví arequipeño: un estudio histórico-social (Arequipa: La Colmena, 1976) 
de poesía que le da origen ${ }^{13}$ y aunque, de otra parte, esté comprobado su temprano mestizamiento ${ }^{14}$ y resulte verosímil la influencia de la poesía española culta de su tiempo. ${ }^{15}$ En todo caso lo sustancial es que el cultivo del yaraví supone la revalorización y uso de una tradición poética nativa - aun si ésta funciona sólo como eslabón primero y muy transformado-y que en tal reivindicación y empleo subyacen filiaciones $\mathrm{y}$ adhesiones absolutamente insólitas en la otra literatura. En este sentido es necesario remarcar que el yaraví no guarda ninguna relación con el paramento indianista que eventualmente aparece en la "literatura de la emancipación".

Es también importante señalar que el yaraví se inscribe dentro del sistema de la literatura popular, pese a que el haber sido cultivado por Melgar ocupó por algún tiempo un lugar dentro de la poesía peruana culta. ${ }^{16} \mathrm{El}$ carácter popular del yaraví está definido, a todas luces, por su ancestro indígena, pero asimismo, aunque en cada caso habría que hacer algunas precisiones, por su condición de poesía para ser cantada, por realizarse en sus instancias de creación, recreación y consumo como "poesía tradicional", ${ }^{17}$ y por la masiva y persistente audiencia que le brindaron las clases media y baja, especialmente en el sur, como se comprueba por la cuantiosa presencia de este género en los cancioneros de la época.

Supuesto lo anterior, es posible reafirmar que los yaravíes melgarianos representan otra opción, harto más significativa, de la literatura de la emancipación - ahora sin comillas. $Y$ esto porque los yaravíes, aunque limitan su ámbito temático al amor, sin contener ninguna alusión a los hechos o ideas de la independencia, ${ }^{18}$ realizan en el plano que específicamente les corresponde como obras literarias esa dimensión emancipadora que la "literatura de la emancipación" proclama pero no

13. He discutido el punto en: "La poesía tradicional y el yaravi" (en Letras, XXXVIII, 76-77, Lima, 1966). En el ya citado libro de Juan Carpio Muñoz se ofrecen otras alternativas.

14. Cf. Consuelo Pagaza Galdo: "El yaravi" (en: Revista de Folklore Americano, VIII-IX, 8-9, Lima, 1960-1961)

15. Jorge Cornejo Polar, "Una fuente desconocida de la poesía de Melgar" (en El Comercio) Suplemento Dominical, Lima, 28 noviembre 1971).

16. Ningún otro cultor del yaraví fue asimilado por el sistema de la literatura peruana culta. Algunos pocos poemas románticos y modernistas se titulan yaravíes, pero en realidad no tienen ninguna relación con el yaraví melgariano y mucho menos con las fuentes de éste.

17. En el sentido que emplea este término Ramón Menéndez Pidal para el romancero. Cf. mi artículo citado en la nota 13.

18. En El yaraví arequipeño (op. cit, pp. 99 y ss.) Juan Carpio Muñoz sostiene que el contenido amoroso del yaraví y hasta algunos de sus símbolos recurrentes expresan la situación social de un grupo indígena-mestizo definido (los lonccos). Aunque no alude a la relación con el proceso emancipador, esta interpretación podría abrir una nueva perspectiva en la que cabría incluir, tangencialmente al menos, algunos componentes temáticos del yaraví dentro de la problemática de la independencia. 
cumple. No otra cosa significa su doble inserción, en lo indígena y en lo popular, en contraste muy marcado con el canon entonces vigente. Queda entendido que esta transformación, pese a realizarse en el espacio de la forma poética, no es solamente una transformación formal: oponer la raíz indígena a la tradición española y reivindicar en la práctica la creación popular frente al cultismo de una literatura fuertemente elitista, son opciones que remiten de inmediato, y con precisión, al plano social. Pensando en ellas Mariátegui afirmó, en polémica con Riva Agüero, que Melgar representaba "el primer momento peruano de esta literatura". ${ }^{19}$

Ciertamente no deja de extrañar que el impulso que produjo el yaraví no suscitara también una literatura explícitamente político-social; ${ }^{20} \sin$ embargo, la escueta existencia del movimiento yaravísta marca la aparición de una conciencia que interpreta la emancipación de otra manera, tanto, que es la intimidad emotiva la que necesita para expresarse el doble apoyo de lo indígena y de lo popular. En última instancia, y aun considerando sus obvias limitaciones e imperfecciones, el yaraví supone un momento histórico en el que algunos hombres deciden plasmar sus afectos en una nueva forma: ya no la española, tal vez sentida ajena e impostada, sino otra que, a través de resonancias remotas pero actuantes, restauraba una tradición por largo tiempo sepultada y revaloraba el modo popular del canto hecho para uno y para todos.

\section{LITERATURA Y SOCIEDAD (II)}

Es indispensable referir la experiencia del yaraví al horizonte social que le corresponde concretamente. No sería suficiente, en efecto, marcar su positiva desviación con respecto a la norma de la "literatura de la emancipación" y explicar ese hecho en una mayor perspicacia políticosocial de Melgar o en su heroica militancia en la rebelión de Pumacahua. Este segundo es dato que debe retenerse, sin duda, pero en sí mismo carece de aptitud explicativa.

La historia oficial ha considerado todas las rebeliones anteriores a 1821 como etapas "precursoras" de la independencia lograda en esa fecha. La imagen que así se obtiene: la de un proceso unitario que parece acumular acontecimientos de significación igual o semejante y que finalmente culmina con el triunfo de los patriotas, es notoriamente falsa. ${ }^{21}$ De hecho

19. Riva Agüero había considerado a Melgar "un momento curioso" dentro de la literatura peruana. Op. cit. p. 23. El juicio de Mariátegui aparece en Siete ensayos... (Op. cit. p. 231)

20. La poesía popular relativa a la emancipación carece del carácter indígena de los yaravíes. Cf. La poesía de la Emancipación, Recopilación y prólogo de Aurelio Miró Quesada (Lima: Comisión Nacional del Sesquicentenario de la Independencia, 1971)

21. Heraclio Bonilla y Karen Spalding, "La independencia en el Perú: las palabras y los hechos" (en La independencia en el Perú, op. cit. pp. 15-64) 
no todas esas rebeliones obedecieron al proyecto criollo que se impuso en 1821 , y algunas de ellas representaron, por el contrario, intereses sociales claramente opuestos. Es el caso, sobre todo, de los movimientos genéricamente reconocibles por su raíz indígena y su base campesina, cuya manifestación mayor es por cierto la rebelión de Túpac Amaru (1780) y dentro de cuyo rumbo se inscribe, parcialmente al menos, el levantamiento de Pumacahua. No cabe ahora caracterizar en detalle este proceso, ${ }^{22}$ pero sí es necesario apuntar su fuerte sentido étnico y el radicalismo de sus propuestas sociales, de manera especial en los momentos en que estuvo impulsado por las masas indígenas.

El yaraví melgariano está profundamente ligado a este otro proceso emancipador - y muy poco, o nada, al proyecto de los criollos. Se explican en él no sólo las opciones claves del yaraví, a favor de lo indígena y lo popular, sino también algunos de sus caracteres formales, como su configuración musical. La preservación de la naturaleza de canción tiene que ver de manera inmediata con la oralidad propia de la cultura popular y repite - salvo por la sustitución de la quena por la guitarra - el modelo indígena tradicional. Es claro que también por esto, que implica un circuito comunicativo sin vínculo consistente con el basado en la lectura, ${ }^{23}$ los yaravíes se diferencian sustancialmente de la "literatura de la emancipación".

El énfasis étnico de los movimientos emancipadores predominantemente indígenas podría explicar también, aunque tangencialmente, el intimismo de los yaravíes. En efecto, al reivindicar un sistema cultural oprimido, estos movimientos ponen en juego no sólo intereses políticos, enmarcados dentro de la dinámica del poder por conquistar, sino también, aunque rara vez de manera orgánica, fuerzas espirituales destinadas a ganar legitimidad para formas determinadas de entender la realidad en su conjunto, incluyendo el lado íntimo de la existencia personal. En los yaravíes se expresa una muy peculiar versión del amor, que tiene componentes determinados por la experiencia histórica del pueblo indígena, ${ }^{24}$ y no sería excesivo considerar esta manifestación específica como parte del impulso legitimador de una cultura.

Todos los movimientos emancipadores de filiación indígena fracasaron pronto; sin embargo, su sola irrupción generó un clarísimo y no

22. Ibidem. Cf. también: Rubén Vargas Ugarte, Historia General del Perú (Lima: Milla Batres, 1966) t. V, Cap. X.

23. Inclusive cuando pasan a la escritura, los yaravíes se difunden en cancioneros, no en libros.

24. Tristeza, fatalismo, despedida y alejamiento de la persona amada, etc. son componentes que pueden referirse a las condiciones de existencia del pueblo indígena y de grupos mestizos pobres. Cf. nota 18. 
injustificado temor en los grupos criollos, tanto por el radicalismo de sus metas cuanto por la violencia de sus procedimientos. De aquí que en el proceso dirigido por los criollos el elemento popular e indígena fuera mantenido a distancia o en condición fuertemente subordinada, a la par que sus intereses no sólo desaparecieron de la agenda republicana, salvo en una que otra declaración teórica, sino que fueron contradichos y burlados aun con más rigor que durante el régimen colonial. La cultura de estos grupos quedó, por consiguiente, oprimida, desprestigiada y sometida a una intensa presión alienadora. El ciclo del yaraví tiene el mismo diseño: floreció mientras los levantamientos indígenas tuvieron espectativas de triunfo y decayó considerablemente, hasta casi desaparecer, cuando la república consolidó los términos de su dominio oligárquico y antipopular. Sólo muchos años después, en momentos de crisis especialmente agudas, como la desatada por la guerra con Chile y sobre todo la que se sitúa entre los años 20 y 30 de este siglo, volverán a surgir alternativas semejantes, pero, por cierto, dentro de otras y muy distintas circunstancias históricas.

\section{SOBRE LA LITERATURA NACIONAL}

La remisión del yaraví melgariano a un proceso social distinto y opuesto al que culmina en 1821, que a su vez tiene sus propias y peculiares manifestaciones literarias, ${ }^{25}$ esclarece las tensiones concretas de una determinada coyuntura histórico-literaria, pero puede servir también para demostrar la no pertinencia teórica de las articulaciones globalizantes entre sociedad y literatura, pues una y otra no son nunca entidades homogéneas, sino estratificadas y fluyentes, hechas de clases y etnias, en un caso, y de sistemas o subsistemas, en el otro, al mismo tiempo que puede servir, igualmente, para confirmar la inconsistencia de las conceptualizaciones de la literatura peruana-y de otras muchas literaturas latinoamericanas-como secuencia unilineal de componentes homogéneos.

Por aferrarse a esta imagen unitaria, que inventa una organicidad a todas luces inexistente, la obra poética de Melgar fue y sigue siendo incomprendida en lo que tiene de mayor valor. Lo normal es, en efecto, situar su poesía patriótica dentro de la "literatura de la emancipación", lo que es correcto, y ubicar los yaravíes como antecedentes del romanticismo, lo que es rigurosamente erróneo, con el fin de inscribir ambas vetas en una sola corriente: la de la literatura peruana culta, en la transición del neoclasicismo al romanticismo. De esta manaera, a más de cortar el

25. Entre éstas habría que incluir al periodismo y a los géneros literarios conectados con él, como el cuadro de costumbres. Cf. Pablo Macera: "El periodismo en la Independencia" (en Trabajos de historia, Lima, INC, 1977, t. 2) 
vínculo entre los yaravíes y la emancipación, porque eso obligaría a hablar de la otra emancipación, se mutila o recorta el significado popular-indígena de estas canciones, gracias a la cual se conserva imperturbable el preconcepto de la unidad de la literatura (y de la sociedad) peruana. "Precursor" de la emancipación y "antecedente" del romanticismo, Melgar es asimilado por el sistema literario culto y por los grupos sociales que con él se identifican. Sólo así accede al espacio consagrado de la literatura nacional.

Uno de los retos más urgentes y más inquietantes de la crítica e historia de las literaturas latinoamericanas consiste en repensar el concepto de literatura nacional y su categoría fundante, la de la unidad, que normalmente no es más que la abusiva y excluyente absolutización de un modo de entender, producir y juzgar la literatura, en desmedro de otros que - por lo menos - son igualmente legítimos y valiosos. En este sentido, al criterio unitario y exclusivista es necesario oponer el de la pluralidad contrastante y conflictiva. Como lo prueba la literatura ligada a la emancipación, el ejercicio de este arte resulta punto menos que ininteligible si se oscurece su condición reproductora de una realidad múltiple y desmembrada y su condición paralela de discurso ideológico inscrito raigalmente en la conflictividad de una sociedad estratificada y pluriétnica. 
